\title{
Accidents and resulting injuries in premobile infants: data from the ALSPAC study
}

\author{
S A Warrington, C M Wright, ALSPAC Study Team
}

\begin{abstract}
Background and aims-Little is known about injuries resulting from accidents in premobile infants. We aimed to describe the pattern of minor accidents in infants and their resulting injuries.

Methods-The ALSPAC study collected data in successive postal questionnaires. At 6 months of age, parents were asked to describe any accident since birth. The type of fall, distance fallen, resulting injury, and help sought were independently coded. Burns were similarly coded. Results-A total of 11466 responses were available. In 2554 children, 3357 falls were reported; $53 \%$ fell from beds or settees and $12 \%$ fell from arms or while being carried. Only $14 \%$ reported visible injury, of which $56 \%$ were bruises; $97 \%$ of injuries specified involved the head. Only 21 falls $(<1 \%)$ resulted in concussion or fracture. A burn or scald occurred in 172 cases $(1.5 \%)$. The main causes of scalds were hot drinks and water, with contact burns caused by radiators, cookers, and hot food.

Conclusions-Falls in young infants are common while burns are rare. Injuries from falls are infrequent, predominantly trivial, and almost entirely confined to the head. Falls from beds and settees did not result in skull fractures. Serious injury was the result of complex accidents. (Arch Dis Child 2001;85:104-107)
\end{abstract}

Keywords: accident; burn; fall; injury

Unintentional injury in childhood is a major public health problem, but little is known about patterns of accidental injury in infancy. The UK government proposed to reduce the death rate for accidents among children aged under 15 years by at least $33 \%$ by $2005 .{ }^{1}$ The annual National Health Service cost of unintentional injury to children in England and Wales has been estimated at $£ 200$ million per annum. ${ }^{2}$ Serious injuries represent only the tip of the iceberg of accidental injury. Any strategy to reduce the injuries caused by accidents is limited by the lack of information about the pattern of trivial and moderate injuries, many of which do not present to medical attention.

There is little information about the pattern of injury to infants associated with domestic accidents with which to compare possible nonaccidental injury, particularly in infants of less than 6 months, who are not mobile. There is only one study on accidents and their associated injuries in infants under 6 months of age, ${ }^{3}$ but as this was a hospital based study, it excluded minor injuries or accidents that did not result in an injury. In the 1-4 year old age group, burns are the leading cause of death in the home environment, ${ }^{4}$ but most epidemiological studies on burns and scalds refer to the population as a whole although some do break down children into under and over 5 year olds.

Non-accidental injury is a rare but important cause of morbidity and death in infancy. The understanding of the normal pattern of accidental injury may be important when questioning whether injuries are consistent with accidental causation or whether non-accidental injury needs to be considered. Suspicions may be aroused if an injury seems out of proportion to the alleged cause. As both non-accidental and accidental head injury may produce similar types of injuries, distinguishing between them is not easy. ${ }^{5}$ Features such as retinal haemorrhages, ${ }^{6}$ depressed or complex fractures, ${ }^{7}$ and associated findings such as failure to thrive and metaphysial fractures, ${ }^{8}$ may make the diagnosis of abuse more obvious. In the absence of these findings, however, the diagnosis rests on recognising discrepancies between the history given and the injury incurred. ${ }^{5}$ Similarly, nonaccidental injuries may be a cause of burns. ${ }^{9}$

This paper draws on a large infancy dataset, which included questions about accidents at 6 months of age. The aims of this study were to define the frequency and severity of accidental injuries from burns and falls, and to describe the accidents which caused them in a premobile age group.

\section{Methods}

ALSPAC (the Avon Longitudinal Study of Parents and Children, formerly the Avon Longitudinal Study of Pregnancy and Childhood) is a major epidemiological study of over 14000 babies which recruited subjects from an early stage of pregnancy. ${ }^{10}$ The population studied was geographically defined as resident in the three Bristol based health districts of Avon, born between April 1991 and December 1992. The number of pregnancies enrolled in the study was 14541 , an estimated $85-90 \%$ of the eligible population. In all, 13822 mothers are still being followed, together with their 14009 children.

Information in the ALSPAC study was linked from questionnaires, medical records, and biological samples to enable studies of the way in which different aspects of the environment affect the health, development, and wellbeing of children and their parents. A series of postal questionnaires at different ages (4 weeks, 6 months, 15 months, 18 months) were used to gather data about a wide range of variables. The questionnaire administered at 6 


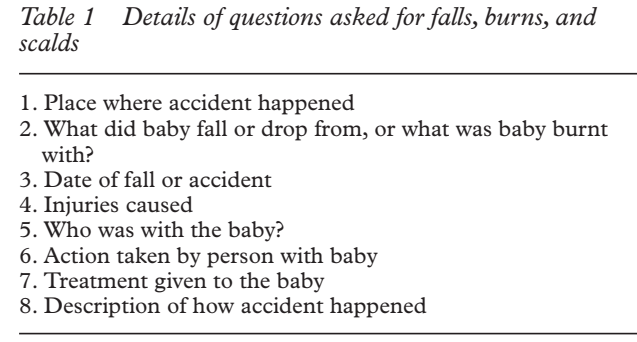

months collected data on falls and injuries, burns, and scalds and these data are the subject of this paper. This age was chosen in order to study a wholly non-ambulant population.

At the age of 6 months mothers were asked to describe any accident that had occurred since birth. Specific details were requested about every accident involving a burn or scald, being dropped or falling, and having any other accidents or injuries. Table 1 gives details of the questions asked. This information was entered unaltered onto an Access database. A description of how the accident happened was requested as free text. These items of text were converted into standardised categories as follows.

Falls-Responses to question 2 in table 1 supplemented with question 8 were used to group similar falls into standard codes in a "fell from" category; for example, armchairs, sofas, and settees were collectively classed as settees. Falls from arms were grouped into those involving stairs, those not involving stairs, and falls from a child's arms. The text from question 4 was broken down into the "site" of the injury and the "injury type". These comprised marks, blows, bumps, abrasions, cuts, bleeds, carpet burns, bruises, concussion (concussion, head injury), and fractures (including suspected fractures).

Burns - For burns and scalds, questions were asked as detailed in table 1 . The accidents were then grouped by cause: contact burns from hot objects (radiators, cookers, food, pans, taps, irons, electrical, and others), scalds from contact with hot liquids or vapours (drinks, water, steam, soup, and baths), and sunburn. Burns from flames and cigarettes were grouped separately. Children described as having sunburn but no injury were excluded from the analysis. Coding of injuries caused was difficult as, for example, scalds could be reported as causing "blisters", "burns", or "scalds" as well as no injury.

Each question was coded independently without reference to parents' responses to other questions, by hiding all other variables during the coding process. For example, during coding of the injuries resulting from falls (both nature and site of the injury), the details of how the accident occurred remained hidden. This was to ensure that responses to one question did not bias the assessment of other responses.

In some cases questionnaires were returned long after the intended time. We therefore excluded 23 falls and two burns reported as occurring after the age of 10 months. Details of age were incomplete for 356 falls and 19 burns.
Table 2 Commonest causes of falls

\begin{tabular}{lcr}
\hline Fell from & Number & (\%) \\
\hline Bed & 1117 & $(33.0)$ \\
Settee & 665 & $(19.7)$ \\
Arms & 203 & $(6.0)$ \\
Arms of child & 133 & $(3.9)$ \\
Arms on stairs & 56 & $(1.7)$ \\
Fell over & 190 & $(5.6)$ \\
Baby chair & 170 & $(5.0)$ \\
Chair & 117 & $(3.5)$ \\
Table & 93 & $(2.8)$ \\
Work top & 48 & $(1.4)$ \\
Changing unit & 43 & $(1.3)$ \\
Pram & 77 & $(2.3)$ \\
Bouncer & 70 & $(2.1)$ \\
Baby walker & 50 & $(1.5)$ \\
Pushchair & 49 & $(1.4)$ \\
Lap & 48 & $(1.4)$ \\
\hline
\end{tabular}

\section{Results}

FALLS

Data were available for analysis on 11466 infants, $81 \%$ of the total study cohort. A total of 3357 falls were reported for 2554 children ( $22 \%$ of the total); $78 \%$ of infants sustained no falls. Of the mothers reporting falls, $76 \%$ reported one fall, and only $5 \%$ had three or more falls.

The commonest types of falls were from beds or settees (table 2). Falls from tables, chairs, and worktops represented a similar type of fall but from a greater height. These include accidents when the infant was placed in a baby chair on the surface and both the chair and the baby then fell off. In nearly $12 \%$ of falls the baby was dropped out of arms or a person fell carrying the baby but did not drop the baby. Older siblings carrying an infant was a common cause of falls from arms. Falls from baby bouncers often occurred when the poppers came undone or the baby was dropped while being put into or taken out of the bouncer. There was no detail of the type of fall in less than $1 \%$ of falls.

The incidence of accidents rose with age up to 6 months. Over half the accidents reported occurred between 5 and 7 months, with less than a quarter in children under 4 months.

Information about injury received was available from mothers in 3202 (95\%) falls, and injury type was unspecified in 156 cases. An injury was sustained in only 437 cases, and 244 $(56 \%)$ of these were bruises. Serious injury, defined as concussion or fracture, occurred in only 21 cases, less than $1 \%$ of all falls. In 206 cases the actual site of injury was not specified. The commonest site of injury was the head in 375 cases $(97 \%)$, with the remaining injuries being to the leg (five cases), arm (four cases), neck, collarbone, and bottom (one case each).

Following their fall, 162 children were taken to hospital and 18 were admitted. The explanations given by the parent for the injury ranged from a detailed description of a fall causing a long bone injury to one case where the parents simply stated that the baby fell out of arms sustaining a skull fracture, with no other explanation given. Three children apparently had skull fractures and were not admitted to hospital. 
Table 3 Numbers of burns or scalds

\begin{tabular}{lrr}
\hline & Number & $(\%)$ \\
\hline Scalds & & \\
$\quad$ Drink & 57 & $(33.1)$ \\
Water & 22 & $(12.8)$ \\
Steam & 2 & $(1.2)$ \\
Soup & 2 & $(1.2)$ \\
$\quad$ Bath & 1 & $(0.6)$ \\
Contact & & $(11.6)$ \\
Radiator & 20 & $(7.0)$ \\
Cooker & 12 & $(7.0)$ \\
Food & 12 & $(4.7)$ \\
Kettle/pan & 8 & $(2.9)$ \\
Tap & 5 & $(2.3)$ \\
Iron & 4 & $(0.6)$ \\
Electrical & 1 & $(4.7)$ \\
$\quad$ Other & 8 & $(5.8)$ \\
Sun & 10 & $(2.9)$ \\
Flame & 5 & $(1.2)$ \\
Cigarette & 2 & $(0.6)$ \\
Not known & 1 & \\
\hline
\end{tabular}

BURNS

A total of 11446 mothers replied to a direct question about burns or scalds, of which only 166 infants $(1.5 \%)$ sustained a burn or scald (172 events). Scalds accounted for 84 events, and contact burns for 70 events (table 3 ). The commonest hazards were hot drinks, hot water, and radiators. Insufficient data were given about the injuries to separate reliably significant from trivial injuries. However, only one child required skin grafting and one other child required dressings for two weeks. Sixteen other children had a dressing or bandage applied to the burn, though some of these were applied at home. Fifteen children attended hospital, but the treatment received is not always clear.

\section{Discussion}

This study reveals that falls in infants are common. Most falls occurred from beds or settees and had an increasing incidence around 6 months of age. Most falls resulted in no injury and serious injuries were very rare. Burns and scalds occurred rarely in young infants, the commonest hazards being hot drinks, hot water, and radiators.

The strengths of this study were its large numbers (over 14000 subjects), its near complete population coverage, and its non-reliance on referral or use of medical services. However, the method of data collection had limitations. Most data had to be extracted from free text with variable amounts of detail provided by parents. This had the potential for events being misclassified, although oversubjective judgements were prevented by each item being classified independently of other variables. Because of reliance on parental recall, the time interval between the accident and completing the questionnaire may have influenced responses. A number of accidents occurred close to or even after the age at which the questionnaire was received, suggesting that mothers may preferentially report recent accidents. It has been shown ${ }^{11}$ that informants have considerable difficulty in remembering all "minor accidents" occurring in a four week reference period. An increased injury rate has been noted during the second six months of life, ${ }^{12}$ when infants begin crawling and walking. For more serious falls the parents may have an inaccurate understanding of injuries treated in hospital, and in some cases there could have been deliberate concealment of non-accidental injury.

However, our findings were consistent with the literature, where comparison was possible. Most previous studies had been hospital based, and as only a minority of accidents result in serious injury or hospital attendance, these studies will therefore have identified only the tip of the iceberg. ${ }^{3}{ }^{13-15}$ One small community based study of 177 infants, ${ }^{16}$ found that the prevalence of bruising in babies aged 6-12 months was $12 \%$, and over $75 \%$ were on the face and head. There was a highly significant increase in bruises with increasing mobility.

The mechanism of falling in this age group reflects their immobility and stage of development, with the commonest causes being rolling off surfaces or being dropped. The vast majority fell off beds and settees, and the damage was therefore limited as had been shown previously. ${ }^{17}{ }^{18}$ It has been suggested that falls from less than 10 feet result in predominantly trivial injuries, ${ }^{19}{ }^{20}$ although falls of $4-5$ feet have resulted in skull fractures. ${ }^{19}$ Chadwick et al reported deaths following falls of 4 feet or less, but concluded these histories were falsified. ${ }^{21}$ Tarantino et al reported mainly minor injuries from short falls in infants. ${ }^{22}$ Most children who fell down stairways sustained minor injuries, involving mainly the head and neck. ${ }^{23}$ This is in keeping with our data where the majority of falls led to no serious injury, but some head injuries did not always seem consistent with the seriousness of the fall.

In a hospital study of accidents at all ages, Maddocks et al found that $43 \%$ of children with injuries had fallen, and most only needed minor treatment or reassurance. ${ }^{13}$ Those under 1 year of age were grouped together, giving a total of 38 infants from a population of around 60001 year olds. Our study focused on infants of 6 months and less from a population of nearly 11500 children. Both studies indicated that serious accidental injury in this age group is uncommon.

In a study from Seattle, ${ }^{14}$ inclusion was determined by injury rather than by a population based history of a fall. The setting of our study was very different, but similarly found that unintentional injuries were rarely serious.

This study has implications both for accident prevention and for the diagnosis of nonaccidental injury. The messages for accident prevention are an awareness of potential mobility even below 6 months, and the dangers of raised surfaces.

In routine clinical practice, when a child is brought to medical attention with an injury the question arises whether non-accidental injury needs to be considered. The occurrence of an intracranial injury in infants, in the absence of a history of significant accidental trauma, such as a motor vehicle accident, has been suggested as grounds for a child abuse investigation. ${ }^{24}$

In this study only one fracture resulted from over 1700 falls from beds and settees: a fractured clavicle. There were no head injuries. Thus uncomplicated falls from low surfaces 
resulting in skull fractures should be regarded as suspicious. When fractures occurred, they resulted predominantly from complex accidents, and therefore it is expected that a detailed circumstantial history would be available. There was one accidental death which was not included in this cohort. This resulted from a complex accident at the age of 4 months.

Burns and scalds occurred much less frequently than falls in infants. Previous studies of scald and burn injuries in children of all ages have found that children under the age of 1 year account for up to $20 \%$ of scalds and burn injuries $^{92526}$; a study of children younger than 5 years hospitalised for a burn injury, found children under 6 months forming just $5 \%$ of all cases. ${ }^{27}$ This highlights the important role of development in determining risk as, before the age of 6 months, the infant's acquisition of motor skills makes them unlikely to encounter a hot object. Other studies have reported a higher burn rate in children under 2 years..$^{28-30}$ These studies were burns unit based and are the more severe end of the spectrum.

In summary, accidents were surprisingly common in infants of 6 months and less. The majority of these accidents were falls, which occurred in $22 \%$ of infants. However, injuries were infrequent, generally trivial, and almost entirely confined to the head. Serious injuries (namely concussion and fractures) were seen in less than $1 \%$ of falls.

The authors wish to thank Dr Philip Lowe for assistance with the database, and Professor Stephen Jarvis and Dr Elizabeth
Towner for advice and encouragement. We are extremely grateful to all the mothers who took part and to the midwives for their ful to all the mothers who took part and to the midwives for their cooperation and help in recruitment. The whole ALSPAC study team comprises interviewers, computer technicians, laboratory technicians, clerical workers, research scientists, volunteers, and managers who continue to make the study possible. This study could not have been undertaken without the financial support of the Wellcome Trust, the Department of Health, the Department of the Environment, British Gas, and other companies. The ALSPAC study is part of the WHO initi

1 Secretary of State for Health. The health of the nation: a strat egy for health in England Cm 1986. London: HMSO, 1992. 2 CAPT (Child Accident Prevention Trust). The NHS and social costs of children's accidents. A pilot study. London: CAPT, 1992:49.

3 Stewart G, Meert K, Rosenberg N. Trauma in infants less than three months of age. Pediatr Emerg Care 1993;9:199 201
4 US Department of Health, Education and Welfare, Public Health Service, Division of Planning and Standards, Environmental Epidemiology Branch. Reports on the epidemiology and surveillance of injuries, No. FY 71-R3, September, 1970

5 Klein DM. Central nervous system injuries. In: Ellerstein NS (ed.), Child abuse and neglect: a medical reference. New York: John Wiley and Sons, 1981:73-93.

6 Caffey J. The whiplash shaken infant syndrome. Pediatrics 1974;54:396-403.

7 Hobbs CJ. Skull fracture and the diagnosis of abuse. Arch Dis Child 1984;59:246-52.

8 Kempe CH, Silverman FN, Steele BF, et al. The battered child syndrome. $7 A M A$ 1962;181:105-12.

9 Datubo-Brown DD, Gowar JP. Contact burns in children. Burns 1989;15:285-6.

10 Golding J, Pembrey M, Jones R, and the ALSPAC Study Team. ALSPAC - the Avon Longitudinal Study of Parents and Children. I. Study methodology. Paediatr Perinat Epidemiol 2001;15:74-87.

11 Health survey for England 1995, Volume I, Chapter 5. London: HMSO, 1995.

12 McCormick MC, Shapiro S, Starfield BH. Injury and its correlates among 1-year-old children. Am F Dis Child 1981; 135:159-63.

13 Maddocks GB, Sibert JR, Brown BM. A four week study of accidents to children in South Glamorgan. Public Health 1978;92:171-6.

14 Rivara FP, Kamitsulka MD, Quan L. Injuries to children younger than 1 year of age. Paediatrics 1988;81:93-7.

15 Carter YH, Jones PW. Accidents among children under five years old: a general practice based study in north Staffordshire. Br f Gen Pract 1993;43:159-63.

16 Carpenter RF. The prevalence and distribution of bruising in babies. Arch Dis Child 1999;80:363-6.

17 Helfer RE, Slovis TL, Black M. Injuries resulting when small children fall out of bed. Pediatrics 1977;60:533-5.

18 Nimityongskul P, Anderson LD. The likelihood of injuries when children fall out of bed. F Pediatr Orthop 1987;7: 184-6.

19 Williams RA. Injuries in infants and small children resulting from witnessed and corroborated free falls. F Trauma 1991; 31:1350-2.

20 Lyons TJ, Oates RK. Falling out of bed: a relatively benign occurrence. Pediatrics 1993;92:125-7.

21 Chadwick DL, Chin S, Salerno C, et al. Deaths from falls in children: how far is fatal? $\mathcal{F}$ Trauma 1991;31:1353-5.

22 Tarantino CA, Dowd MD, Murdock TC. Short vertical falls in infants. Pediatr Emerg Care 1999;15:5-8.

23 Joffe M, Ludwig S. Stairway injuries in children. Pediatrics 1988;82:457-61.

24 Billmire ME, Myers PA. Serious head injury in infants: accident or abuse? Pediatrics 1985;75:340-2.

25 Phillips W, Mahairas E, Hunt D, Pegg SP. The epidemiology of childhood scalds in Brisbane. Burns 1986;12:343-50.

26 Banco L, Lapidus G, Zavoski R, Braddock M. Burn injuries among children in an urban emergency department. Pediatr Emerg Care 1994;10:98-101.

27 Simon PA, Baron RC. Age as a risk factor for burn injury requiring hospitalization during early childhood. Arch Pediatr Adolesc Med 1994;148:394-7.

28 Rossignol AM, Locke JA, Burke JF. Paediatric burn injuries in New England. Burns 1990;16:41-8.

29 Lindblad BE, Terkelsen CJ. Domestic burns among children. Burns 1990;16:254-6.

30 Cronin KJ, Butler PEM, McHugh M, Edwards G. A 1-year prospective study of burns in an Irish paediatric burns unit. Burns 1996;22:221-4. 